\section{Infectious Disease Opportunity}

Director of System Epidemiology - Infection Control

Geisinger Health System, a nationally recognized leader in quality initiatives, is seeking a BC/BE Infectious Disease Physician to provide medical leadership of an Infection Control Program in an expanding multi-hospital healthcare system. The ideal candidate will possess data analysis skills and have prior experience in an environment which emphasizes quality healthcare delivery. This position will include inpatient ID responsibilities. An advanced degree (MPH) is desirable but not required dependent upon the applicant's qualifications.

\section{Geisinger Health System Includes:}

- Geisinger Medical Center, Danville, PA, a 408-bed, Level I tertiary/quaternary care center that includes the Weis Center for Research, Janet Weis Children's Hospital, and the Center for Health Research.

- Geisinger Wyoming Valley, Wilkes-Barre, PA, a 177-bed acute care community hospital nestled on the edge of the Pocono Mountains. It includes a freestanding heart hospital, a comprehensive cancer center and the Janet Weis Children's Hospital pediatric wing.

- Geisinger South Wilkes-Barre, Wilkes-Barre, PA, a acute care community hospital that is licensed for 190 beds, with an additional 20 skilled nursing beds and a 10 -bed Adolescent Psychiatry Unit. GSWB offers a wide range of services including an Emergency Department, a fully accredited Sleep Disorders Center, and a Heart Center featuring comprehensive diagnostic, cardiac catheterization laboratory, surgical and cardiac rehabilitation.

- Geisinger Community Practice, more than 40 single and multispecialty physician offices throughout northeastern and central Pennsylvania.

- Teaching opportunities through our 75 medical and surgical specialties and 23 accredited residency and fellowship programs.

- Opportunities for clinical trials and outcomes research through Geisinger Center for Health Research and the Weis Center for Research.

Geisinger offers physicians:

- An MPH program in conjunction with The Johns Hopkins Bloomberg School of Public Health. The opportunity to pursue this training would be supported for the appropriate candidate.

- The opportunity to utilize a mature, fully-integrated electronic health record - connecting a comprehensive network of more than 40 community medical groups and an integrated network of over 650 Geisinger primary and specialty physicians.

- Paid medical malpractice insurance with tail coverage.

- Excellent benefits package including 4 weeks vacation and 3 weeks CME annually (with stipend)

- The benefits of Pennsylvania living — good schools and affordable homes in nice neighborhoods-just an afternoon's drive from the Poconos, New York City, Philadelphia and Washington, DC.

At Geisinger, you'll experience the support, camaraderie and professional challenges of a leading practice while discovering the charms of Pennsylvania living.

To discuss this opportunity, contact:

Kathy Kardisco, Recruiter

Geisinger Department of Professional Staffing,

100 North Academy Avenue, Danville, PA 17822-2428

Phone: I-800-845-7| I2 - Fax: I-800-622-25I5

e-mail:kkardisco@geisinger.edu

Geisinger is a drug-screening employer; EOEIM/FID/V.
C I as ified Ads

Asst, Assoc Professor/Stewardship Director

UNIVERSITY OF NEBRASKA MEDICAL CENTER

Assistant/Associate Professor/Hospital Epidemiology/ Antimicrobial Stewardship Director: Applications are invited for a faculty position in the Department of Internal Medicine, Infectious Diseases Section at the University of Nebraska Medical Center (UNMC) to lead the Antimicrobial Stewardship Program. The successful applicant will be appointed as an Associate Hospital Epidemiologist in the Department of Healthcare Epidemiology at The Nebraska Medical Center. Generous protected time and support are available in order to achieve the goals of the program. Participation in the clinical, teaching, and research programs of the Infectious Diseases Section and the Department of Healthcare Epidemiology is expected. Applicants are encouraged to visit the UNMC and Nebraska Medical Center websites at www.unmc.edu or www.nebraskamed.com. Candidates should send a CV and cover letter to: Mark E. Rupp, M.D.; UNMC; Department of Internal Medicine; Infectious Diseases Section; 984031 Nebraska Medical Center; Omaha, NE 68198-4031; E-mail: merupp@unmc.edu. UNMC is an affirmative action/equal opportunity employer. Women and minorities are encouraged to apply.

\section{Classified Advertising Information}

\section{Classified Rates}

$1 \mathrm{x}-\$ 200$ for 50 words or less; $\$ 1.00$ for each word over 50

$3 x-\$ 175$ for 50 words or less; $\$ 1.00$ for each word over 50

$6 x-\$ 150$ for 50 words or less; $\$ 1.00$ for each word over 50

\section{Typesetting Services}

All classified ads are typeset in the same font and format. However, bold, italicized and underlined typefaces are available for $50 \varnothing$ extra per word.

\section{Word Count}

In calculating your cost, we define a word as one or more letters surrounded by spaces. Below are some examples:

Maria A. Johnson, MD

October 9, 2003

773-702-7600

Chicago, IL 60637

a

multi-specialty

qualifications/experience

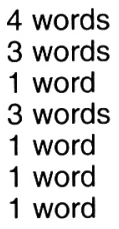

To place a classified ad, or for more information, please contact:

Tanya Thompson

The University of Chicago Press

Phone: 773-702-7956

Fax: 773-702-0172

thompson@press.uchicago.edu 


\section{Clinical}

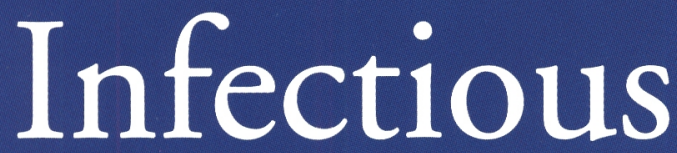

Diseases

Official publication of the Infectious Diseases Society of America

Clinical Infectious Diseases (CID) publishes topical research and incisive commentaries from distinguished clinicians and scientists on the diagnosis and treatment of infectious diseases. Each issue contains clinically relevant articles of current interest in:

- Clinical Research

- Immune Mechanisms

- Medical Microbiology

- Epidemiology and Prevention

- Pathogenesis

- HIVIAIDS

- New Antimicrobial Therapies

\section{CID Online}

Read a sample issue, sign up for RSS feeds, register for e-TOC tables of contents alerts, and use UpToDate, the free "topic link" information service - all online at www.journals.uchicago.edu/CID.

\section{To Subscribe:}

Phone: (877) 705-1878 (US/Canada), or (773) 753-3347 (International)

Fax: (877) $705-1879$ (US/Canada), or (773) 753-0811 (International)

Online: www.journals.uchicago.edu/CID E-mail: subscriptions@press.uchicago.edu
Providing Timely

Information on Clinical

Topics and Infectious

Disease Research

Editor, Sherwood L. Gorbach

Tufts University School of Medicine

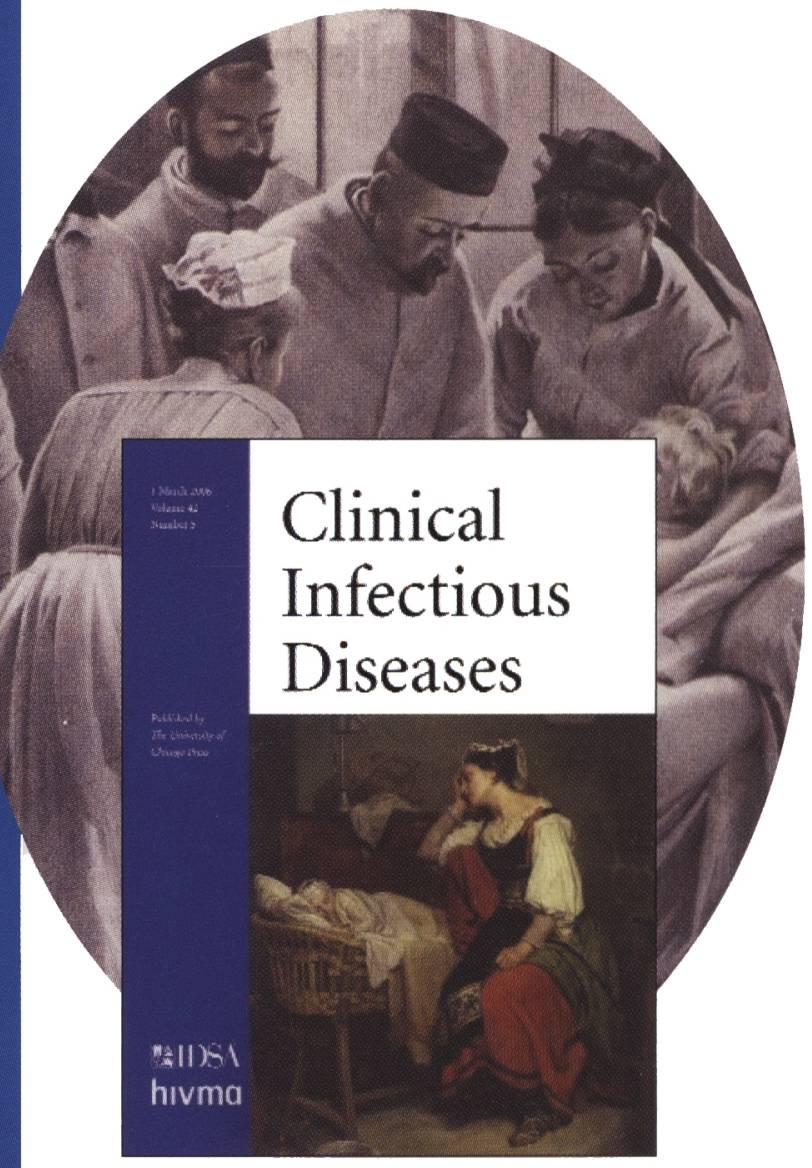

Semimonthly. ISSN: 1058-4838.



The University of Chicago Press

Journals Division

P.O. Box 37005, Chicago, IL 60637

www.journals.uchicago.edu 


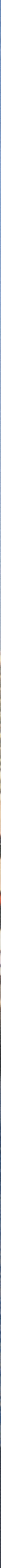

